\title{
PERFIL DE SUSCETIBILIDADE AOS ANTIMICROBIANOS EM INFECÇÕES COMUNITÁRIAS DO TRATO URINÁRIO EM MULHERES DA CIDADE DE ANÁPOLIS/GO
}

ANTIMICROBIAL SUSCEPTIBILITY PROFILE IN COMMUNITY URINARY TRACT INECTIONS IN WOMEN FROM THE CITY OF ANÁPOLIS/GO

Eliane Pureza Lemes (LEMES, E. P.) - eliane100lemes@ hotmail.com

Graduada em Farmácia - Centro Universitário de Anápolis - UniEVANGÉLICA

Jéssica Araújo Matos (MATOS, J. A.) - jessicaamatos_@hotmail.com

Graduada em Farmácia - Centro Universitário de Anápolis - UniEVANGÉLICA Ana Luiza Rodrigues Ramos (RAMOS, A. L. R) - analuizafaria@ @ hotmail.com Graduada em Farmácia - Centro Universitário de Anápolis - UniEVANGÉLICA Bruna Helena Ferreira Ponce (PONCE, B. H. F.) - helena hponce@ hotmail.com Discente de Farmácia- Centro Universitário de Anápolis - UniEVANGÉLICA Aline de Araújo Freitas (FREITAS, A. A.) - alinefreitas2@ gmail.com Professora do Centro Universitário de Anápolis - UniEVANGÉLICA Kelly Deyse Segati (SEGATI, K. D.) - kelly.segati@docente.unievangelica.edu.br Professora do Centro Universitário de Anápolis - UniEVANGÉLICA

Emerith Mayra Hungria Pinto (PINTO, E. M. H.) - emerith0706@ hotmail.com Professora do Centro Universitário de Anápolis - UniEVANGÉLICA

\section{Endereço para correspondência}

AV. Universitária Km 3,5 Cidade Universitária - Anápolis/GO CEP 75083. Bloco F

\section{RESUMO}

Introdução: A infecção do trato urinário (ITU) é a segunda infecção mais comum na população em geral e apresenta uma alta prevalência em mulheres. As enterobactérias são os agentes mais envolvidos. Objetivo: Avaliar o perfil de suscetibilidade antimicrobiana in vitro de enterobactérias isoladas de uroculturas. Métodos: Estudo descritivo transversal realizado no período de agosto a dezembro de 2017 no Laboratório de Análises Clínicas da UniEVANGÉLICA. Amostras de urina de jato médio de 333 pacientes do sexo feminino, com pedidos de urocultura foram semeadas nos meios de cultura apropriados para isolamento. 
A identificação dos bacilos Gram negativos foi realizada por meio do Sistema Bactray® e o antibiograma foi realizado pelo método Kirby-Bauer. Resultados: Foram isoladas enterobactérias em 13,2\% (n=44) das amostras analisadas. Com relação a identificação, a maioria dos isolados foram de E. coli $(65,9 \%$; 29/44), seguidos por Klebsiella sp. $(9,1 \%$; 4/44), Acinetobacter baumannii (9,1\%; 4/44), Morganella morganii $(9,1 \%$; 4/44) e Hafnia alvei $(6,8 \%$; 3/44). O maior percentual de resistência das enterobactérias isoladas foi observado para ampicilina, seguido da celafosporina de primeira geração (cefalotina), norfloxacina e ciprofloxacina. Das enterobactérias isoladas, 40\% (12/30) apresentaram resistência a dois ou mais fármacos de classes diferentes, sendo que oito isolados de $E$. coli demonstraram multirresistência. Conclusões: A $E$. coli foi a enterobactéria mais frequentemente isolada e com perfil de resistência a múltiplos fármacos.

Palavras-chave: Antibiograma; E. coli; Infecção urinária; Resistência bacteriana.

\begin{abstract}
Introduction: Urinary tract infection (UTI) is the second most common infection in the general population and has a high prevalence in women. Enterobacteria are the most involved agents. Objective: To evaluate the in vitro antimicrobial susceptibility profile of enterobacteria isolated from urine cultures. Methods: Cross-sectional descriptive study carried out from August to December 2017 at the Clinical Analysis Laboratory of UniEVANGÉLICA. Urine samples from 333 female patients with urine culture orders were seeded in the appropriate culture media for isolation. Gram negative bacilli were identified using the Bactray ${ }^{\circledR}$ System and the antibiogram was performed using the Kirby - Bauer method. Results: In 13.2\% ( $=44)$ of the samples, enterobacteria were isolated. Regarding identification, most isolates were E. coli $(65.9 \%$; 29/44), followed by Klebsiella sp. (9.1\%; 4/44), Acinetobacter baumannii $(9.1 \% ; 4 / 44)$, Morganella morganii $(9.1 \% ; 4 / 44)$ and Hafnia alvei $(6.8 \% ; 3 / 44)$. The highest percentage of resistance of isolated enterobacteria was observed for ampicillin, followed by first generation cellelaphosporin (cephalothin), norfloxacin and ciprofloxacin. Of the isolated enterobacteria, $40 \%$ (12/30) showed resistance to two or more drugs of different classes, with eight isolates of E. coli showing multidrug resistance Conclusions: E. coli was the most frequently isolated enterobacterium with a resistance profile to multiple drugs.
\end{abstract}


Keywords: Antibiogram; E. coli; Urinary infection; Bacterial resistance.

\section{INTRODUÇÃO}

As Infecções do Trato Urinário (ITU) são a segunda maior causa de infecções adquiridas na comunidade e apresentam maior prevalência em mulheres, especialmente no início da vida sexual e na gravidez. (BITENCOURT e PAVANELLI, 2014). Atingem cerca de 150 milhões de pessoas ao ano em todo o mundo, causando desgaste econômico e danos extensos a saúde dos pacientes. (RIZWAN et al., 2018; MORAES et al., 2014).

A principal via de contaminação do trato urinário é a via ascendente, que na mulher é propiciada pela menor extensão anatômica da uretra e pela maior proximidade entre a vagina e o ânus. (ALMADA et al., 2017). A ITU pode ser assintomática ou sintomática sendo os quadros sintomáticos caracterizados por redução do volume de urina, polaciúria, disúria, urgência miccional, nictúria e dor suprapúbica. (TUON et al., 2015).

Os agentes causadores da ITU geralmente pertencem a microbiota do próprio paciente sendo representados principalmente pelos membros da família Enterobacteriaceae. (ANVISA, 2004). A enterobactéria Escherichia coli é o agente mais frequentemente isolado, além de outros microrganismos, como Staphylococcus saprophyticus, Proteus sp. e Klebsiella $s p$., que também estão presentes em menor porcentagem, seguidos pelo Staphylococcus aureus. (BITENCOURT e PAVANELLI, 2014).

O diagnóstico laboratorial da ITU é realizado mediante urocultura e teste de sensibilidade in vitro a antimicrobianos (TSA), entretanto algumas diretrizes estabelecem que ITU baixa não complicada em mulheres pode ser tratada empiricamente. Nos casos de falha do tratamento empírico a urocultura e o TSA ganham maior importância, visto que orientarão a nova conduta terapêutica.(ALVES et al., 2016).

A ocorrência de ITU constitui uma das principais causas de consulta médica e de prescrição de antimicrobianos, o que acarreta grandes impactos socioeconômicos individuais e sociais. (ENNIS et al., 2018). A alta incidência da ITU, sua sintomatologia desconfortável e demora dos exames laboratoriais contribuem para o tratamento empírico e uso generalizado de antimicrobianos. Esses fatores colaboram para o aumento da incidência da resistência bacteriana na população em geral. (JENSEN et al., 2018; KHOSHNOODA et al., 2017).

O tratamento empírico racional necessita do conhecimento dos principais agentes etiológicos envolvidos nos quadros de ITU e do perfil de resistência aos antibióticos. Portanto, para o sucesso do tratamento empírico é necessário o monitoramento periódico, 
visto que os uropatógenos e o padrão de sensibilidade aos antimicrobianos varia com o tempo e em cada região geográfica. Nesse sentido, o objetivo desse estudo foi avaliar o perfil de sensibilidade antimicrobiana in vitro de enterobactérias isoladas de uroculturas de pacientes atendidas em um laboratório de análises clínicas.

\section{METODOLOGIA}

Trata-se de um estudo prospectivo, de caráter descritivo de delineamento transversal realizado com amostras de urina de pacientes do sexo feminino encaminhadas pelo Sistema Único de Saúde (SUS) ao Laboratório de Análises Clínicas da UniEVANGÉLICA em Anápolis- GO, durante o período de agosto a dezembro de 2017.

As amostras de urina foram submetidas a urocultura seguindo as recomendações da ANVISA (2010). O isolamento dos microrganismos foi realizado em ágar CLED (cistinalactose eletrólito deficiente) e MacConkey com incubação em estufa bacteriológica à temperatura de $37^{\circ} \mathrm{C} \pm 1^{\circ} \mathrm{C}$ por 24 horas. As culturas com crescimento igual ou superior a $10^{5}$ $\mathrm{UFC} / \mathrm{mL}$ foram consideradas positivas e encaminhadas para a identificação bacteriana pelo sistema comercial Bactray®.

O TSA foi realizado pelo método qualitativo de disco difusão (Kirby- Bauer) em ágar Müeller Hinton. Os antimicrobianos avaliados foram ampicilina, cefalotina, ciprofloxacino, cloranfenicol, gentamicina, norfloxacina e sulfazotrim. As placas foram incubadas à temperatura de $37^{\circ} \mathrm{C} \pm 1^{\circ} \mathrm{C}$ por 24 horas. Após a incubação os halos de inibição foram medidos e sua interpretação seguiu os padrões recomendados pelo Clinical and Laboratory Standards Institute (CLSI) - Performance Standards for Antimicrobial Susceptibility Testing de 2017.

O presente estudo foi aprovado Comitê de Ética em Pesquisa (CEP) da UniEVANGÉLICA com no de parecer: 2.147.426.

\section{RESULTADOS E DISCUSSÃO}

No período de agosto a dezembro de 2017 foram recebidos no Laboratório de Análises Clínicas da UniEVANGÉLICA 333 pedidos de urocultura de pacientes do sexo feminino, provenientes do município de Anápolis/GO, com faixa etária de 18 a 86 anos. O isolamento bacteriano foi realizado para $44(13 \%)$ amostras de urina, conforme descrito na Tabela 1. 
Tabela 1 - Perfil das pacientes com urocultura positiva no laboratório de Análises Clínicas da UniEVANGÉLICA entre agosto e dezembro de 2017.

\begin{tabular}{ccc}
\hline Idade (anos) & n & \% \\
\hline Jovens $18-29$ & 13 & 29,5 \\
Adultas $30-59$ & 22 & 50 \\
Idosas $60-86$ & 9 & 20,5 \\
Total & 44 & 100 \\
\hline
\end{tabular}

A bactéria mais frequentemente isolada dentre as 44 amostras com crescimento bacteriano acima de $10^{5} \mathrm{UFC} / \mathrm{mL}$ foi a Escherichia coli $(\mathrm{n}=29,66 \%)$, seguida de Klebsiella sp. ( $\mathrm{n}=4 ; 49 \%)$, Acinetobacter baumannii $(\mathrm{n}=4 ; 9 \%)$, Morganella morganii $(\mathrm{n}=4 ; 9 \%)$ e Hafnia alvei que foi isolada em três amostras (n=3; 7\%) (Figura 1).

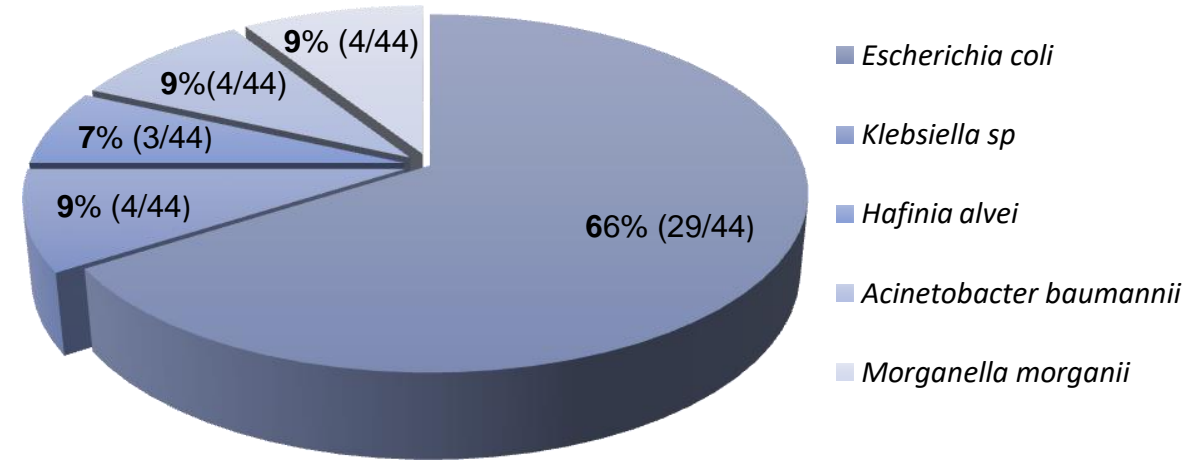

Figura 1- Enterobactérias isoladas das amostras de urina no laboratório de Análises Clínicas da UniEVANGÉLICA entre agosto e dezembro de 2017.

A prevalência de E. coli na ITU é bem documentada e concordante com os resultados de outros estudos. Rocha e colaboradores em 2017 encontraram uma prevalência de 67,4\% de E. coli nos isolados provenientes de amostra urinária assim como Moraes e colaboradores (2014) que isolaram E. coli em $61 \%$ das uroculturas de pacientes ambulatoriais em Jataí-GO. (MORAES et al., 2014).

A alta prevalência de E. coli em isolados de mulheres com ITU pode estar relacionada com alterações hormonais, fatores comportamentais e características anatômicas da mulher, como uretra curta e a proximidade desta com ânus, favorecendo o alcance das enterobactérias, pertencentes à microbiota intestinal humana. (MORAES et al., 2014). A 
prevalência da bacteriúria na mulher adulta aumenta com a idade e a ITU recorrente é relativamente comum nas mulheres representando $80 \%$ dos casos de infecção por bactérias oriundas dos reservatórios retal e vaginal, com ocorrência mais provável quando há alterações anatômicas ou funcionais do trato urinário. (PALMA, 2002).

No presente estudo, o TSA foi realizado para 30 das 44 amostras de urina positivas e o perfil de suscetibilidade aos antimicrobianos das enterobactérias isoladas é demonstrado na figura 2. O maior percentual de resistência das enterobactérias isoladas foi observado para ampicilina, seguido da celafosporina de primeira geração (cefalotina), norfloxacina e ciprofloxacina. Uma maior porcentagem de resistência frente a ampicilina e cefalotina era esperada, uma vez que os beta-lactâmicos são facilmente hidrolisados pelas beta-lactamases expressas especialmente pelas bactérias Gram negativas. (VIEIRA E VIEIRA, 2017). As cefalosporinas de $3^{\mathrm{a}}$ e $4^{\mathrm{a}}$ geração são mais ativas contra enterobactérias por serem mais estáveis à hidrólise por beta-lactamases apresentando, portanto, menor percentual de resistência (BRUNTON, L. L; CHABNER, B.A; KNOLLANN B.C., 2012).

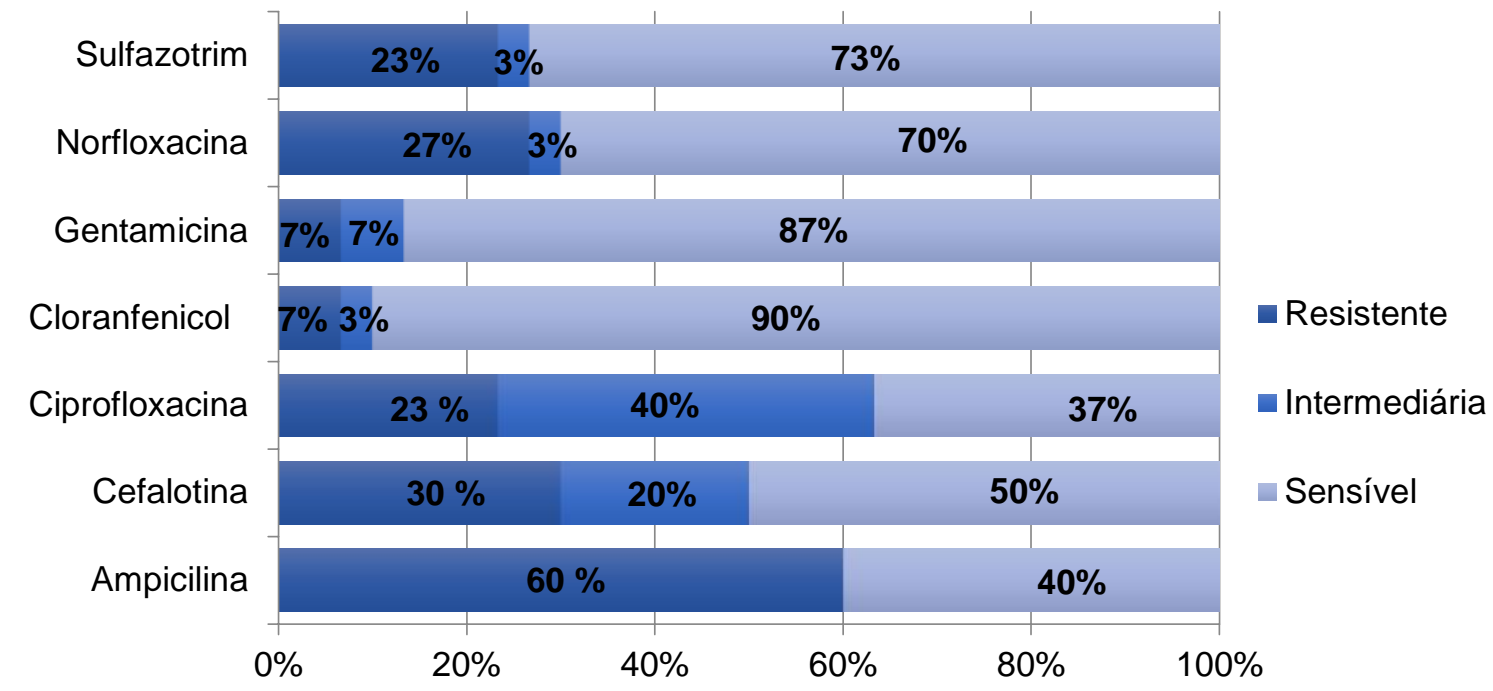

Figura 2 - Perfil de suscetibilidade das enterobactérias frente aos antimicrobianos avaliados no laboratório de Análises Clínicas da UniEVANGÉLICA entre agosto e dezembro de 2017.

Na tabela 2 são descritos os dados do perfil de suscetibilidade de cada espécie bacteriana isolada frente aos antimicrobianos testados. Dos isolados testados, 40\% (12/30) apresentaram resistência a dois ou mais fármacos de classes diferentes. Oito isolados de $E$. coli, demonstraram multirresistência, com destaque para uma paciente idosa (61 anos), com diabetes, em que o isolado foi resistente a todos os antimicrobianos testados. 
Todos isolados de Acinetobacter baumannii, um de Hafnia alvei e um de Morganella morganii demonstraram multirresistência. Dentre os casos de multirresistência, a resistência as quinolonas está presente em sete de doze casos. Entre as combinações de multirresistência encontramos: Ampicilina + Gentamicina; Ampicilina + Cefalotina, Ciprofloxacino/Norfloxacino + Sulfazotrim; Ampicilina + Cefalotina + Ciprofloxacina/Norfloxacina + Cloranfenicol + Sulfazotrim.

Tabela 2 - Perfil de resistência antimicrobiana dos principais uropatógenos isolados de pacientes atendidas no Laboratório de Análises Clínicas da UniEVANGÉLICA entre agosto e dezembro de 2017.

\begin{tabular}{cccccc}
\hline Antimicrobiano & $\begin{array}{c}\text { E. coli } \\
(\mathbf{n = 1 8})\end{array}$ & $\begin{array}{c}\text { Acinetobacter } \\
\text { baumannii } \\
(\mathbf{n = 2})\end{array}$ & $\begin{array}{c}\text { Klebsiella sp } \\
(\mathbf{n = 4})\end{array}$ & $\begin{array}{c}\text { Morganella } \\
\text { morganii } \\
(\mathbf{n = 3})\end{array}$ & $\begin{array}{c}\text { Hafnia } \\
\text { alvei } \\
(\mathbf{n}=\mathbf{3})\end{array}$ \\
\hline Ampicilina & $67 \%$ & $100 \%$ & $75 \%$ & - & $33 \%$ \\
Cefalotina & $33 \%$ & $50 \%$ & - & $33 \%$ & $33 \%$ \\
Ciprofloxacina & $28 \%$ & - & $25 \%$ & $33 \%$ & - \\
Cloranfenicol & $11 \%$ & - & - & - & - \\
Gentamicina & $6 \%$ & $50 \%$ & - & - & - \\
Norfloxacina & $33 \%$ & - & $75 \%$ & $33 \%$ & - \\
Sulfazotrim & $28 \%$ & - & - & $33 \%$ & $33 \%$ \\
\hline
\end{tabular}

Em nosso estudo as cepas de E. coli apresentaram a maior resistência à Ampicilina (67\%), seguidos de cefalotina e norfloxacina (33\%) e ciprofloxacina e sulfazotrim (28\%). Estudo conduzido por Moraes e colaboradores em 2014 descreveu índices de resistência de 57,9\% para Ampicilina e 44,8\% para Sulfazotrim, respectivamente. Em 2018, CHEN et al., avaliando 32 antimicrobianos frente a isolados de urocultura demonstraram altos percentuais de resistência de E. coli frente a ciprofloxacina e levofloxacina, ampicilina, sulfazotrim, aztreonam e cefalosporinas. (REF de Moraes e Chen).

A existência de bactérias resistentes à diversos antimicrobianos levou as autoridades de saúde de alguns países a controlarem o uso desses fármacos. Estudo com médicos atuantes na Atenção Básica do município de Divinópolis (MG) constatou que os antimicrobianos de primeira escolha para tratamento empírico de cistite não complicada em adultos são Norfloxacino (56,1\%), seguido por Sulfazotrim (19,3\%), e Ciprofloxacino (10,5\%), indicando que a exposição frequente de $E$. coli a esses fármacos é responsável pela seleção cada vez mais frequente de cepas resistentes. (FERREIRA et al., 2015) favorecendo o desenvolvimento de resistência a outras classes de antimicrobianos como as quinolonas, o que é preocupante, pois, afeta a antibioticoterapia de emergência. (BITENCOURT e PAVANELLI 2014). 
Em nosso estudo não houve diferença estatística no perfil de sensibilidade aos antimicrobianos nas diversas faixas etárias, por outro lado, em estudo realizado por Lo et al., (2013) foi observado uma prevalência crescente de resistência com o aumento da idade. O risco de infecções bacterianas resistentes aos medicamentos em idosos são resultados de um contato frequente com sistemas/unidades de saúde, presença de doenças crônicas que debilitam a função imunológica, a imunossenescência e uso de dispositivos de demora que propiciam a colonização bacteriana. Além disso, em muitos casos, esses pacientes já foram expostos a múltiplos antibióticos ao longo da vida (GIARRATANO et al. 2018)

\section{CONCLUSÃO}

A enterobactéria E. coli foi o microrganismo mais comumente isolado das uroculturas, seguido por Klebsiella sp, Acinetobacter Baumanii, Morganella morganii e Hafinia alvei. Com relação ao perfil de suscetibilidade aos antimicrobianos das enterobactérias isoladas, o maior percentual de resistência foi observado para ampicilina, seguido da celafosporina de primeira geração (cefalotina), norfloxacina e ciprofloxacina. Cepas de E. coli isoladas apresentaram resistência a múltiplos fármacos.

O conhecimento dos uropatógenos e seu perfil de sensibilidade aos antimicrobianos minimizam as falhas no tratamento e ainda o surgimento de cepas bacterianas resistentes, reduzindo a antibioticoterapia empírica e contribuindo para a promoção do uso racional dos antimicrobianos. Além disso, a importância do tratamento correto ao longo da vida reduz as taxas de resistência bacteriana na fase idosa e garante um tratamento eficaz com o uso de antimicrobianos.

\section{REFERÊNCIAS BIBLIOGRÁFICAS}

1. ALMADA, D. V. et al. Perfil de resistência a antimicrobianos em pacientes atendidos em um laboratório privado no município de Santa Inês-MA. Revista UNINGÁ Review, [S.L], v. 30, n. 3, p. 10-14, abr./jun. 2017. Disponível em: <http://revista.uninga.br/index.php/uningareviews/article/view/2036>. Acesso em: 20 abr. 2018.

2. ANVISA. Antimicrobianos - base teóricas e uso clínico. Brasília 2007. Disponível em: <http://www.anvisa.gov.br/servicosaude/controle/rede_rm/cursos/rm_controle/opas_web/

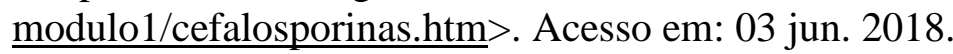


3. ANVISA. Procedimentos Laboratoriais - Requisição do exame a análise microbiológica. Brasília, 2004. Disponível em:

<http://www.anvisa.gov.br/servicosaude/manuais/microbiologia/mod_3_2004>.pdf.

Acesso em: 12 jun. 2018.

4. ALVES, M.S.A; EDELWEISS, M.K; BOTELHO, L.J. Infecções comunitárias do trato urinário: prevalência e susceptibilidade aos antimicrobianos na cidade de Florianópolis. Rev Bras Med Fam Comunidade, Rio de Janeiro, v. 11(38), p. 1-12, 2016. Disponível em: https://www.rbmfc.org.br/rbmfc/article/view/1187/788. Acesso em 11 de maio de 2021.

5. BITENCOURT, J. D. S; PAVANELLI, M. F. Urinary infection in patients of public health care of Campo Mourão-PR, Brazil: bacterial prevalence and sensitivity profile. $J$ Bras Patol Med Lab, Rio de Janeiro, v. 50, n. 5, p. 346-351, 2014. Disponível em: <http://www.scielo.br/scielo.php?script=sci_arttext\&pid=S1676-24442014000500346>. Acesso em: 17 abr. 2018.

6. BRUNTON, L. L; CHABNER, B.A; KNOLLANN B.C. Goodman \& Gilman: As Bases Farmacológicas da Terapêutica. 12a ed. Rio de Janeiro: McGraw-Hill, 2012.

7. CHEN, D. et al. The analysis of microbial spectrum and antibiotic resistance of uropathogens isolated from patients with urinary stones. Int J Clin Pract, 2018;72:e13205. Disponível em: https://onlinelibrary.wiley.com/doi/epdf/10.1111/ijcp.13205. Acesso em 05 set 2018.

8. ENNIS, S. S. et al. Premenopausal women with recurrent urinary tract infections have lower quality of life. Int J Urol, 2018 Jul;25(7):684-689. Disponível em: <https://www.ncbi.nlm.nih.gov/pubmed/29788547>. Acesso em: 28 mai. 2018.

9. FERREIRA, V. M. et al. Infecções comunitárias do trato urinário em Divinópolis, MG: Avaliação do perfil de resistência bacteriana e do manejo clínico. Rev Bras Med Fam Comunidade. Rio de Janeiro, 2017 Jan-Dez; 12(39):1-13. Disponível em: <https://www.rbmfc.org.br/rbmfc/article/view/1553>. Acesso em: 17 abr. 2018.

10. GIARRATANO, A. et al. Review of antimicrobial use and considerations in the elderly population. Clinical Interventions in Aging, Nova Zelândia, 2018:13, p. 657-667. Disponível em: 〈https://www.ncbi.nlm.nih.gov/pubmed/29713150〉. Acesso em: 26 mai. 2018.

11. JENSEN, J. N. et al. Comparison of antibiotic prescribing and antimicrobial resistance in 
urinary tract infections at the municipal level among women in two Nordic regions. $J$ Antimicrob Chemother. 2018 Ago 1; 73 (8): 2207-2214. Disponível em:

<https://www.ncbi.nlm.nih.gov/pubmed/29757408>. Acesso em: 28 mai. 2018.

12. KHOSHNOODA, S. et al. Drug-resistant gram-negative uropathogens: A review. Biomedicine \& Pharmacotherapy 94 (2017) 982-994. Disponível em:

<https://www.sciencedirect.com/science/article/abs/pii/S0753332217335783 >. Acesso em: 20 abr. 2018.

13. LO, D. S. et al. Infecção urinária comunitária: etiologia segundo idade e sexo. J Bras Nefrol 2013;35(2):93-98. Disponível em: <http://www.scielo.br/scielo.php?pid=S010128002013000200003>. Acesso em: 17 abr. 2018.

14. MORAES, D. et al. Prevalence of uropathogens and antimicrobial susceptibility profile in outpatient from Jataí-GO. J Bras Patol Med Lab, v. 50, n. 3, p. 200-204, junho 2014. Disponível em: 〈http://www.scielo.br/scielo.php?script=sci_arttext $>$. Acesso em: 17 jan. 2018.

15. OLIVEIRA, A. L. D. et al. Mecanismos de resistência bacteriana a antibióticos na infecção urinária. Revista UNINGÁ Review Vol.20,n.3,pp.65-71 (Out - Dez 2014). Disponível em: 〈https://www.mastereditora.com.br/periodico/20141130_221311.pdf>. Acesso em: 28 mai. 2018.

16. PALMA P.C.R, Dambros M. Cistites nas mulher. Ver Bras Med. 2002;59:346-50.

17. RIZWAN, M. et al. Escherichia coli and Klebsiella pneumoniae Sensitivity/Resistance Pattern Towards Antimicrobial Agents in Primary and Simple Urinary Tract Infection Patients Visiting University Hospital of Jamia Hamdard New Delhi. US National Library of Medicine National Institutes of Health, New York, mar. 2018. Disponível em: <https://www.ncbi.nlm.nih.gov/pubmed/29529677>. Acesso em: 17 abr. 2018.

18. TUON, F. F.; ROCHA, J. L.; MERLINI, A. B. Combined therapy for multi-drug-resistant Acinetobacter baumannii infection - is there evidence outside the laboratory?. Journal of Medical Microbiology (2015), 64, 951-959. Disponível em:

<https://www.ncbi.nlm.nih.gov/pubmed/26220079>. Acesso em: 03 jun. 2018.

19. VIEIRA, P. N.; VIEIRA, S. L. V. Uso irracional e resistência a antimicrobianos em hospitais. Arq. Cienc. Saúde UNIPAR, Umuarama, v.21, n. 3, p, 209-212, set./dez. 2017. Disponível em: 〈http://revistas.unipar.br/index.php/saude/article/view/6130>. Acesso em: 03 jun. 2018. 